ISSN 2076-0787

www.mdpi.com/journal/humanities

Essay

\title{
From Literature to Cultural Literacy ${ }^{1}$
}

\author{
Naomi Segal \\ Department of Cultures and Languages, School of Arts, Birkbeck University of London, WC1H 0PD \\ London, UK; E-Mail: n.segal@bbk.ac.uk \\ Academic Editor: Cinzia Ferrini
}

Received: 4 November 2014 / Accepted: 17 December 2014 / Published: 4 February 2015

\begin{abstract}
In recent years, the academic field of literary studies has changed radically. Literary scholars are now working on objects other than poems, dramas or fiction. This essay presents an ongoing strategic project, Cultural Literacy in Contemporary Europe, which was founded in 2007 and run in 2009-11 as an European Science Foundation \& Cooperation in Science and Technology (ESF-COST) synergy. Its aim is to investigate and celebrate the range of research currently being conducted in the field we have renamed "literary-and-cultural studies", or LCS. This research aims to enhance cultural literacy. Cultural literacy is an attitude to the social and cultural phenomena that shape our existence-bodies of knowledge, fields of social action, individuals or groups, and of course cultural artefacts, including texts-which views them as being essentially readable: it is a way of looking at social and cultural issues, especially issues of change and mobility, through the lens of literary thinking. The project focuses on four academic fields - cultural memory, migration and translation, electronic textuality, and biopolitics and the body - and four concepts: textuality, fictionality, rhetoricity and historicity. It stresses multilingualism and is part of the movement of interdisciplinarity within the humanities and between the humanities and other disciplines, but remains a distinctive activity within that larger movement.
\end{abstract}

Keywords: cultural literacy; textuality; rhetoricity; fictionality; cultural memory; electronic textuality; migration; interdisciplinarity; multilingualism; comparative studies

1 A version of this essay was presented at the workshop Funding policies and research values: strategies and needs, risks and prospects at the University of Trieste, 12 May 2014, under the title 'Cross-disciplinary Humanities: Strategies for and Strategies of Cultural Literacy'. Some of the material included has also appeared in two other publications: [1] and [2]. 


\section{Introduction}

Picture a researcher in an international academic forum-perhaps an interdisciplinary research committee or assessment panel—who is asked, over coffee or during the opening tour de table, to describe her research field. If, like me, she is from the UK, she would give little real information by saying "I'm in a School of Modern Languages" or "an English department". It might make more sense to describe the field in which she got her undergraduate and research degrees as "literary studies". But if the next question is "And what are you working on now?" the answer might be anything from "trauma museums" to "TV vampires", or even from "buried bones" to "the psychology of skin".

The project I shall present in this essay was first formed in 2007 to chart the activities of a large group of humanities scholars. These scholars began their academic life in literary studies and have now taken literary questions into areas well beyond the philological study of literary texts. In doing so, they are entering the field of strategic developments in humanities across (and beyond) Europe and of course across (and beyond) their own discipline. The project aims to make this activity more visible and to explore ways of taking it further.

\section{Problems of Literary Studies within European Research}

In October 2007, it came to the notice of the Standing Committee for the Humanities of the European Science Foundation (ESF) that there was a "problem" with literature. They had observed that relatively few literary applications were coming in to any of their funding schemes and that, among those that did, an even smaller proportion were successful. Rather than decide this meant that little research of any value was going on in the literary field, the Committee proposed to create a Working Group on literary studies, and this group first met in St. Gallen, in Switzerland. It consisted of four Standing Committee members who were all literary scholars, from the Czech Republic, Hungary, Switzerland and the UK. After initial discussions, the Working Group reported to the Standing Committee Plenary meeting a day later that it had taken on a threefold objective: to analyse the status quo and problems of the literary field in the humanities; to find a working definition of "literary studies"; and to look into possibilities of developing a strategy to support literary studies in the context of the ESF.

First of all: what was the problem? The group felt it was a combination of two issues: that literary researchers are not much used to networking and that we are poor at lobbying because we do not have a clear enough sense of ourselves as a field. It seemed that the problem lay in the very richness and variety of the research being conducted. Literary researchers are, if you like, the archetypal "lone scholars", reading being an intrinsically solo activity, and very often an interdisciplinary world can reside in a single skull - and thus the many debates and collaborations that we do undertake may not be effectively presented as such, to ourselves or to others. It was also felt that our invisibility goes back to the failure to conceive, as a discipline that is a multiplicity of disciplines, that there is a core coherence to what we do. It is not that literary researchers do not contribute to analysing and intervening in social problems - including the "great challenges" of the moment - but they are inexperienced in lobbying and in presenting their achievements, both past and future. As the issues became defined in the first Strategic Workshop, held in London a year later, a key fourth issue emerged: how can we take credit 
for the social benefits we actually do produce, and how can we develop the field's potential for social added-value?

From the start, the group decided on two main working definitions. The first was to rename our field "literary and cultural studies" (LCS) — cultural studies being understood here as a humanities field of research rather than, as originally conceived in 1964 in Birmingham, as a branch of social science. The second was to present four key concepts that characterize both the material that LCS scholars work on and the ways in which they work on it - textuality, fictionality, rhetoricity and historicity. Central to all this is the fact that our work remains that of readers: our job is still to criticize, analyse and synthesize.

\section{A Century of Change in Literary Studies}

At this point, it may be useful to look briefly at the changes in how literary studies have been practised over the last century. In less than a hundred years, the academic field of literary studies has seen many radical shifts. In the first quarter of the twentieth century, Roman Jakobson called for a "science of criticism" that would define what was distinctively literary and T.S. Eliot argued for the impersonality of poetry. In the 1930s and 1940s, critics as diverse as F.R. Leavis, René Wellek and Erich Auerbach took the long view of literature, replacing a stress on the specifics of authors, histories and euvres with a more systematic understanding of how one reads. Such thinkers were defining and thus safeguarding the autonomy of literary studies as a discipline; in this sense they were continuing a line from the ancients. From the 1960s, however, with the rise and adoption of French critical theory, literary studies grew away from the tradition of "pure" philology and textual criticism and began to borrow from other fields, such as anthropology, linguistics, philosophy and psychoanalysis, to find new ways of thinking about its objects and practices. In the next few decades, it became further politicized, reading texts through the lenses of feminism, queer studies, postcolonial studies and so on, and thus came, in turn, to direct the gaze of literature onto other objects.

Fast-forwarding to our own century, let us consider a literary scholar who brings quantitative methods into the study of texts. In 2000, Franco Moretti wrote:

The trouble with close reading (in all of its incarnations, from the new criticism to deconstruction) is that it necessarily depends on an extremely small canon. This may have become an unconscious and invisible premiss by now, but it is an iron one nonetheless: you invest so much in individual texts only if you think that very few of them really matter. Otherwise, it doesn't make sense. And if you want to look beyond the canon [...] close reading will not do it. It's not designed to do it, it's designed to do the opposite. At bottom, it's a theological exercise-very solemn treatment of very few texts taken very seriously_whereas what we really need is a little pact with the devil: we know how to read texts, now let's learn how not to read them. Distant reading: where distance, let me repeat, is a condition of knowledge: it allows you to focus on units that are much smaller or much larger than the text: devices, themes, tropes - or genres and systems. And if, between the very small and the very large, the text itself disappears, well, it is one of those cases when one can justifiably say, Less is more ([3], p. 57). 
The purpose of Moretti's argument is, of course, polemical, but it also cuts a certain Gordian knot, in representing a fresh way to think about literary studies. The text will not disappear; but what is more pertinent to the kind of research the "people formerly known as literary scholars" are doing now is a particular mode of asking questions that we propose to call "cultural literacy".

\section{From Literary Studies to Cultural Literacy}

Cultural literacy is a way of looking at social and cultural issues - especially issues of change and mobility, as we shall see - through the lens of literary thinking. It is a way of finding and making sense, by looking at the textuality, fictionality, rhetoricity and historicity of things. It is part of the general movement of interdisciplinarity within humanities and between humanities and other disciplines, but it is a distinctive activity within that larger movement.

It is common to refer to the competency required to find one's way in the contemporary world with the term "literacy". For all the ubiquity of visual or aural stimuli and messages that bombard us now, especially in urban places, the ability to read things is as indispensable as it ever was - analphabetism is not an option. A quick trawl of the internet defines media literacy as "a repertoire of competences that enable people to analyze [sic], evaluate, and create messages in a wide variety of media modes, genres, and forms" and emotional literacy as "the ability to understand your emotions, the ability to listen to others and 'empathise' ${ }^{2}$ with their emotions, and the ability to express emotions productively" - both supremely practical skills. You can even buy a health literacy checker from the Health Literacy Advisor (HLA) which "streamlines the review and simplification process by allowing users to assess the health literacy of their documents and then fix it using plain language principles"; and on $\mathrm{BBC}$ radio, a speaker referred to the adequate provision of sport in schools as creating "physical literacy". 3

Indeed, Wikipedia offers a history of something called cultural literacy, defined as early as 1987 as "what every American needs to know", two years later as "a terrible idea whose time has come" and in 2009 as a debate to be revisited - with UK author Michael Rosen deploring the likelihood of it entering the school curriculum in October 2012. One site, again offering an upgrade of essential skills, defines cultural literacy, somewhat tautologically, as follows:

How does one become more culturally literate? By reading more, by reading about different subjects [...] when reading becomes a pleasure rather than a chore, one becomes more culturally literate [...] naturally. It's a simple fact that the more one reads, the more one can understand what is read, the more enjoyable reading becomes and [...] the more culturally literate one becomes. ${ }^{4}$

Assuming, as we do, that the readers of this journal do not have to be persuaded to read more or about different subjects, our own definition of cultural literacy is rather different from this. We are not

2 Reference to [4] in the original.

3 Dr Richard Weiler, consultant in sport and exercise medicine at University College London Hospitals, on the BBC radio

4 Today programme on 10 December 2013.

4 These web references are, respectively: "Emotional literacy" [5] citing Claude Steiner [6-8]; citing the listed titles of E.

D. Hirsch, Leila Christenbury and Bernard Schweizer; $[9,10]$. 
talking about increasing your word-power or your ability to claim familiarity with high or popular literature. What we have in mind is an attitude to the social and cultural phenomena that shape and fill our existence-bodies of knowledge, fields of social action, individuals or groups, and of course cultural artefacts, including texts - which views them as being essentially readable. This legibility is defined by the key concepts of textuality, fictionality, rhetoricity and historicity, outlined below, which are understood as properties both of the phenomena themselves and of our ways of investigating them. LCS research highlights communication, comparison and critique, as has the more traditional literary research that preceded it, but it is particularly interested in a scale other than that of one language or one nation-state, moving out from area studies to trans-area studies, towards the globalized or supranational and towards the regional or local. In line with what Zygmunt Bauman has called our age of "liquid modernity" [11], we stress cross-disciplinarity, multilingualism and collaboration. The goal of LCS research is to deploy and enhance cultural literacy.

\section{Phase I: Defining the Specificity of Literary and Cultural Studies}

\subsection{Textuality}

A text is a weave of meanings. The concept of "textuality"-what Roland Barthes describes as a "galaxie de signifiants" (galaxy of signifiers) ([12], p. 12) or Clifford Geertz identifies as the intricate "thickness" of the structures that constitute cultures [13] - represents the complexity of all cultural objects and activities. Whether it is an aesthetic construction or a social process, any cultural object can be understood as an artefact. Textuality may or may not presume a maker; the focus is on the formal shape of the thing. LCS techniques that describe, explain and contextualise such structures are valuable tools for understanding and analysing any social entity, from a law to a bodily gesture.

\subsection{Fictionality}

In cultural meaning there is no fixed ground of materiality; yet the referentiality of many artefacts supposes a difference between the real and unreal that is best described by the term "fictionality". As its Latin root suggests, a fiction is a thing fashioned; like "textuality", it may well assume a maker, but the identification of fictionality does not necessarily focus on authorship. Like other virtual forms, fictionality may be rule-bound in the sense that it presupposes rules of artifice, but it is not bounded by natural laws. A fiction is not a lie, but its truth-claims are not testable. To study the fictionality of any object is to study how kinds of truth-effect are artfully achieved.

\subsection{Rhetoricity}

Assuming language (or similar structures) to have probable purposes and undoubted effects is "rhetoricity". The concept is derived from the art of persuasion through speech-rhetoric-as developed and practised in Greek and Roman antiquity, but it may be extended to any formal or informal techniques that persuade or manipulate. Metaphors and other figures of speech pervade every level of discourse, and they are never innocent: why, for example, do we still speak of "hard" and "soft" sciences? To be able to identify rhetoricity not only as a tool of specialized forms of discourse 
but as a phenomenon that invades all kinds of communication is one of the most important facets of cultural literacy.

\subsection{Historicity}

All human artefacts and practices have extension in time, whether or not they have extension in space. Their freight of past is essential to their meaning. While the age of the "grand narratives" is over, the historicity of things relates to their formation as "little narratives", the quality of being a tale told and heard. Historicity has two faces: it relates both to the synchronous historical context of a socio-cultural phenomenon and to its position in the diachronic processes of change of which it is a part. The study of all these aspects of historicity can make a direct contribution to the process of cultural problem-solving.

In the course of its early development, the project focused on defining and delimiting its field. The ESF group opened initial debates by running a Strategic Workshop for a small number of interested researchers, held at the Institute of Germanic \& Romance Studies in London in October 2008 and attended by twenty invited delegates, a balance of senior and early-career academics, from fourteen countries. Various points emerged as essential to the further development of the project; here are a few:

Attempting to define the specificity of LCS, the members of the London Workshop drew two key conclusions: LCS is the response to forms of subjective cultural expression that combine the particular with the general, but avoid abstraction; and it goes beyond the text to focus, especially, on the inter-discursive and inter-lingual. Considering the relations of LCS to other disciplines, we noted, firstly, that since in the past literary scholars had exported theoretical concepts (gender, postcolonial, cinema/media studies, gay studies, migration, cultural memory), which made our work visible but made it harder to retain our specificity, now is the time to consolidate ties between disciplines by preserving and strengthening our own; and, secondly and connectedly, that if LCS researchers are to collaborate in a bilateral way, other disciplines need to recognize the validity of our methods and not just assume expertise because they "know how to read". How can the exchange of knowledge be genuinely reciprocal - for example, not just turning bioethics on Proust but turning Proust on bioethics?

As far the political and social dimensions of LCS are concerned, our view was that these are many and varied, indeed we already study larger political issues - as the four Workshops will show. We have also moved out in two directions from area studies to trans-area studies - towards the globalized or supranational and towards the regional or local. We must keep an awareness of linguistic diversity and thus we need both more language-learning and better translations; but we remain aware that translation is both loss and gain and that every reading is a translation. And finally, how does LCS already produce values that can change European society? We strongly felt that the ability to change ways of thinking, analyse cultural traditions and inculcate independent thought and hermeneutic competence are all major social values. Such a contribution is not easy to discern, and thus it is urgent that we find ways of making this knowledge transfer explicit, effective and measurable.

To offer another example, in a debate in London a couple of years ago on the dilemmas of implementing new publication methods, one speaker said: "The problem is that we humanities researchers think in words and they-the policy-makers and funders - think in figures". The LCS response to this might be: yes, but of course we need figures too and of course they actually also think 
in words; the way forward is to think together about the rhetoricity of those words and the possible fictionality of those figures.

\section{Phase II: Strategic Activities}

In its next phase, the project took shape as a strategic activity (a "synergy") jointly funded and organised by the Standing Committee for the Humanities of ESF and the Domain of Individuals, Societies, Cultures and Health of COST (European Cooperation in Science and Technology). A Steering Committee of eight academics from seven European countries was created to organise a series of workshops, each itself international and interdisciplinary, to explore four key areas of activity in this new field. For each field, an international workshop was coorganised by one ESF and one COST academic in a different country; each workshop brought together by invitation about twenty participants invited from as many countries as possible, again combining early-career and senior researchers, casting the net wide enough to take in both LCS academics and others from allied or contrasting fields. A brief account of each Workshop and the discussions that emerged, is given below, followed (in italics) by a short version of the summary published in the Science Policy Briefing published by COST and ESF in 2013 [14].

\subsection{Workshop 1: Remembering and Forgetting (London, December 2009)}

At this Workshop, there were 23 delegates, from 13 countries - most of them EU nations (six in Central and Eastern Europe) and also including Turkey. The breadth of the research fields represented is demonstrated by the following list, named in advance by the delegates, which is not exhaustive: social anthropology, "transculture", English literature/Cultural memory, Portuguese studies/conflict, comparative literature, theory, LCS/post-communism, philosophy-literature-politics, politics/translation, Polish literature, Irish literature, Cultural studies/post-socialism, oral history, urban studies/creative writing (poetry), anthropology/linguistics, Italian literature /film, early modern French literature, 20c French literature, psychoanalysis/gender, history, visual culture.

The delegates were asked in advance to summarise their own angle on cultural memory: where it is now and where it is going; how LCS works in this field; and to give their responses to four issues: the truth of memory: fact and fiction; regimes of memory: spaces, texts, objects, bodies; trauma and memory; and the politics and ethics of memory. In addition, they were asked to prepare a 10-min position paper, not necessarily the same as their advance comments - either developing them or taking a different angle. These short papers were deliberately scheduled in sets of four, in alphabetical order of speaker, so as to create arbitrary mixtures of viewpoints in presentation and discussion. There were also three break-out sessions on three "Core Issues"-relations between LCS and cultural memory studies; interdisciplinarity between LCS/CM and other academic fields; and finally, and least modestly: how can LCS/CM change the world?

LCS-informed memory studies can be seen as particularly useful in dealing with situations where conflicting strategies of remembering and forgetting create boundaries and exclusion and thus social and political friction-for example, in the area of ethnic or religious identification. Such situations are ever more frequent in Europe, but societies and 
institutions often lack an awareness of their historical roots and consequently an essential sense of cultural perspective.

\subsection{Workshop 2: Cultural Migration (Dublin, May 2010)}

This Workshop was more circumscribed in field and range of delegates - but its field has more recently been expanded to take in issues of translation (understood in a literal and a metaphorical sense). This connects theory to practice in a very exact way, looks at inter-generational cultural relations within families and societies, and keeps literature in view: who writes in what language, how do they get published, who reads, what new kinds of art can build on literary motives - and not least, why are migrants always expected to be autobiographical...?

"Cultural translation", a term used frequently in LCS, describes processes of spatial mobility and functions as a paradigm in which to situate journeys, migrations, dislocations and re-territorialisation across languages, geographies, identities or social landscapes. In this way, LCS research also re-establishes the importance of agency, demonstrating how in the process of dialogic exchange new voices can emerge, new spaces of cultural production and consumption can be created, and new audiences can be shaped. Translation may thus be understood not as a homogenising tool or a means of converting difference into sameness, but rather as a set of complex practices which allow the heterogeneity of society to remain productive.

\subsection{Workshop 3: Electronic Textuality (Istanbul, June 2010)}

The third Workshop brought together invited delegates from ten countries, four of which were outside Europe: Turkey, Russia, Israel and the USA. It looked at issues of new media in relation both to reading - does the "born-digital" generation read less or more? - and writing - do we write in tiny bites or quite the reverse, unstoppably? It also compared the way we think of interactive media and new forms of creativity in relation, for example, to Barthes' theories which, already in the 1970s, described "old media" in terms now universally viewed as typical only of the new... It considered issues of secondary and higher education, as well as education of academics themselves. And it examined how we are moving, extremely fast, into new ways of editing and publishing.

LCS research enables interdisciplinary perspectives on the transformation of reading and writing, including social-science and empirical research, to explore how different media, textual modalities and forms of access affect the content and interpretation of textual material. [...] One urgent step is to focus the education policies of the European Research Area both on generally improving people's understanding of the linguistic and textual characteristics of this new flow of knowledge and on inculcating ways of detecting and analysing its rhetorical and fictional characteristics. Another is to develop intelligent and critical usage and improved technological fluency on the part of both generations of users, in order to maximise the potential of their research. 


\subsection{Workshop 4: Biopolitics, Biosociality and the Body (St. Gallen, August 2010)}

This Workshop was particularly interdisciplinary, as the field combines LCS researchers with those in history, politics, law and especially medical sciences. As the field of medical humanities grows apace, both clinical practice and the education of doctors and others in the clinical fields is increasingly affected by the useful perspectives brought in by LCS researchers (patients "tell their stories", doctors need to listen and hear them). In the workshop, twenty speakers from ten countries spoke on topics as diverse as grafting; online genetics websites as a form of biohistory; "lifestyling"; human rights; the hijab; law in the genetic era; disability and "perfection"; international nutrition standards; science fiction; psychopathology and literature; masochism; the author's body; the sense of touch; animal studies; body art; narrative in medical records; internal body maps; restless leg syndrome; and the dead body as artefact.

For more than a century, LCS research has actively participated in debates about the body. European research into sexuality and psychology from the 1890s to the 1930s recognised its debts to literary forebears. The term "biopolitics" was coined by Michel Foucault to describe the growing connection between the human body and its cultural contexts, and in 1996 Paul Rabinow defined the concept of "biosociality" as the idea that relations between humanity and its environment are mutual and reciprocal [...]. Based on these terms and their methodological implications, LCS research on the body has a direct link to such non-humanities fields as biology, medicine and healthcare, or to politics and communication technology, as well as to such issues as the cultural history and geography of the senses, the ubiquity of body metaphors, gender and rhetoric and politics of intercorporeal relations, the overlap of the physical and the psychical, and so forth.

\section{Implementing the Project}

Two textual outcomes have emerged so far from the Cultural Literacy project: a collection of 16 essays in four main sections, coedited by Daniela Koleva and me-which was published by Palgrave Macmillan in October 2014 [15] — and the Science Policy Briefing [SPB] cited above [14], which was published by ESF in January 2013.

The aims of an ESF Science Policy Briefing are threefold - to address science policy issues of key concern to Member Organisations and the scientific community; to draw on the advice and expertise of top-level European researchers; and to provide evidence-based strategy recommendations to policy makers. The Cultural Literacy SPB presents the rationale, the history of the four chosen fields, and four recommendations to implement and develop the project.

\subsection{Recommendation 1: Create a Cultural Literacy Conference Series}

A biennial Cultural Literacy Conference series will be created, to be organised under the aegis of a pan-European organisation, and to present, to both LCS researchers and their collaborators in other fields, new research developments, urgent debates, etc. The first of these, bringing together around 80 researchers and policy-makers, will aim to rebrand LCS and create a European Forum for LCS research. 
The organisation of the first conference is already well under way; it will be held at the Birkbeck Institute for the Humanities in London on 16-18 April 2015, and include five keynote lectures, parallel academic seminars and plenary debates centred on a panel of invited policymakers and stakeholders, as well as an art installation and film-showing. Both the conference and the other activities of the project are now organised by an international Steering Committee of five-Arianna Ciula, Nina Kancewicz-Hoffman, Daniela Koleva, Loredana Polezzi and Naomi Segal, who have set up a website at http://cleurope.eu/. The Conference will culminate in the creation of a European Forum, which implements the second Recommendation and sets in motion the discussion and actions that are intended to implement the others.

\subsection{Recommendation 2: Inaugurate a European Forum for LCS Research}

The Forum will be created at the first biennial Conference. Its role will be to develop pan-European strategies of integrating LCS research into the explicitly interdisciplinary strategy of the proposal for Horizon 2020 and into national research strategies. It will be led by LCS researchers, representatives of governmental organisations concerned with grand challenges, \& representatives of major European research funding agencies.

The Forum will be charged, in particular, with devising a European "outward face"-communications, dissemination and web presence; with national strategies (representation in EU countries or areas); with organising future biennial conferences, overseeing publications, etc.; and with the visibility of LCS in relation to Horizon 2020 - The Framework Programme for Research and Innovation-and beyond (in time and space).

\subsection{Recommendation 3: Develop Flexible Funding Instruments}

With the examples outlined in the SPB and an improved understanding of the contribution of LCS research, European and national funding and policy-making agencies will be invited to introduce smaller-scale, flexible funding instruments corresponding to the needs of the LCS community. These are excellent value for money, allowing scholars to create or enhance collaborations, pursue individual research or update skills. Examples are ESF Exploratory Workshops, research leave schemes \& COST networking.

At the risk of swimming against the tide, we want to stress the importance of "small is beautiful" in research funding. LCS research is comparatively cheap to support, having low-cost infrastructural needs in comparison to that of the natural sciences. The essential elements which cannot be covered by institutional support are funding for time and collaboration: updating of technical skills, research leave, research travel and other forms of networking. The financial modesty of these needs has led, paradoxically, to their being seen as less urgent or less important than larger demands. However, they offer remarkable value for money for a relatively small outlay.

\subsection{Recommendation 4: Embed Cultural Literacy in Higher Education}

Higher education models providing students from non-LCS programmes with access to LCS curricula will be promoted. These may include undergraduate courses, postgraduate 
seminars, student-led conferences or collaboration with external bodies such as schools, governmental or non-governmental organisations. Examples: studium generale courses at Amsterdam, Lisbon and St. Gallen; ESF SCH "Humanities Spring" debates for early-career researchers.

\section{Conclusions: The Way Forward}

It is clear-and this chimes in especially with the Europe 2020 strategy target of improving education across Europe - that more groundwork needs to be done at earlier stages of the higher education system. Students as well as researchers need to learn how to present their discipline and understand it and its relation to other disciplines. What is proposed here is to create a more coherent and systematic introduction to Cultural Literacy for all students from all disciplines, to be implemented across Europe.

So where does the project stand at present? With two publications under its belt, and the first Conference being organized by its five-person Steering Committee, it is currently funded by a grant from the ESF Scientific Review Group in Humanities and is supported, in addition, by a number of other partner organisations: the Academia Europaea (AE), the federation of All European Academies (ALLEA), COST, the European Association for Digital Humanities (EADH), the European Consortium for Humanities Institutes and Centres (ECHIC), the International Comparative Literature Association (ICLA), the Universities of Roehampton and Sofia and Warwick University's Connecting Cultures Research Priority Programme.

Collaboration, especially at international level, is the life-blood of such a project — working together with other organisations that are campaigning for the same inclusion and visibility of humanities research. But our key aim is to highlight a distinctive kind of research. For this, the key element is visibility: to make the work of LCS researchers visible to both their colleagues and themselves is the essential goal of Cultural Literacy in Europe.

\section{Conflicts of Interest}

The author declares no conflict of interest.

\section{References}

1. Naomi Segal. “Cultural literacy-where next?” In Pensar a Liter@tura no Séc XXI. Edited by João Amadeu Silva, José Cândido Martins and Miguel Gonçalves. Braga: Aletheia 2011, pp. 69-80.

2. Naomi Segal. "Introduction." In From Literature to Cultural Literacy. Edited by Naomi Segal and Daniela Koleva. London: Palgrave Macmillan, 2014, pp. 1-12.

3. Franco Moretti. "Conjectures on world literature.” New Left Review 1 (2000): 54-68.

4. Wikipedia. "Empathy." Available online: http://en.wikipedia.org/wiki/Empathise (accessed on 4 October 2014).

5. Wikipedia. "Emotional literacy." Available online: http://en.wikipedia.org/wiki/Emotional_ literacy (accessed on 9 December 2013). 
6. Claude Steiner, and Paul Perry. Achieving Emotional Literacy. London: Bloomsbury, 1997.

7. Wikipedia. "The Health Literacy Advisor." Available online: http://healthliteracyinnovations. com/products/hla (accessed on 9 December 2013).

8. Wikipedia. "Cultural literacy." Available online: http://en.wikipedia.org/wiki/Cultural_literacy (accessed on 9 December 2013).

9. Michael Rosen. "O gawd, here comes 'Cultural Literacy' again.” 20 October 2012. Available online: http://michaelrosenblog.blogspot.it/2012/10/o-gawd-here-comes-cultural-literacy.html (accessed on 24 December 2014).

10. The Literacy Company. "Cultural Literacy Tests." Available Online: http://www.readfaster. com/culturalliteracy/ (accessed on 9 December 2013).

11. Zygmunt Bauman. Liquid Modernity. Cambridge: Polity, 2000.

12. Roland Barthes. S/Z. Paris: Seuil, 1970.

13. Cifford Geertz. "Thick Description: Toward an Interpretive Theory of Culture." In The Interpretation of Cultures: Selected Essays. New York: Basic Books, 1973, pp. 3-30.

14. European Science Foundation. "Cultural Literacy in Europe today." Available online: http://www.esf.org/fileadmin/Public_documents/Publications/spb48_Cultural_Literacy.pdf (accessed 8 December 2013).

15. Naomi Segal, and Daniela Koleva, eds. From Literature to Cultural Literacy. London: Palgrave Macmillan, 2014.

(C) 2015 by the author; licensee MDPI, Basel, Switzerland. This article is an open access article distributed under the terms and conditions of the Creative Commons Attribution license (http://creativecommons.org/licenses/by/4.0/). 